Article

\title{
Lingonberry Fruit Ethanol Extract Ameliorates DSS-Induced Ulcerative Colitis In Vivo and In Vitro
}

\author{
Yong-Deok Jeon ${ }^{1}$, Ji-Hyun Lee ${ }^{2}$, Sa-Haeng Kang ${ }^{3}$, Hyun Myung ${ }^{4, *}$ and Jong-Sik Jin ${ }^{3, *(D)}$ \\ 1 Department of Korean Pharmacy, College of Pharmacy, Woosuk University, 443 Samrye-ro, Samrye-eup, \\ Wanju-gun 55338, Jeollabuk-do, Korea; ydjeon1211jh@woosuk.ac.kr \\ 2 Department of Immunology, Institute of Medical Science, Jeonbuk National University Medical School, 20, \\ Geonji-ro, Deokjin-gu, Jeonju-si 54907, Jeollabuk-do, Korea; jihyunsh1211@naver.com \\ 3 Department of Oriental Medicine Resources, Jeonbuk National University, 79 Gobong-ro, \\ Iksan 54596, Jeollabuk-do, Korea; rkdtkgod@naver.com \\ 4 Department of Ecology Landscape Architecture-Design, Jeonbuk National University, 79 Gobong-ro, \\ Iksan 54596, Jeollabuk-do, Korea \\ * Correspondence: mh98@jbnu.ac.kr (H.M.); jongsik.jin@jbnu.ac.kr (J.-S.J.); Tel.: +82-63-850-0737 (H.M.); \\ +82-63-850-0744 (J.-S.J.)
}

check for updates

Citation: Jeon, Y.-D.; Lee, J.-H.; Kang, S.-H.; Myung, H.; Jin, J.-S. Lingonberry Fruit Ethanol Extract Ameliorates DSS-Induced Ulcerative Colitis In Vivo and In Vitro. Appl. Sci. 2021, 11, 7955. https://doi.org/ 10.3390/app11177955

Academic Editor: Giovanna Traina

Received: 6 August 2021

Accepted: 27 August 2021

Published: 28 August 2021

Publisher's Note: MDPI stays neutral with regard to jurisdictional claims in published maps and institutional affiliations.

Copyright: (c) 2021 by the authors. Licensee MDPI, Basel, Switzerland. This article is an open access article distributed under the terms and conditions of the Creative Commons Attribution (CC BY) license (https:// creativecommons.org/licenses/by/ $4.0 /)$.

\begin{abstract}
Ulcerative colitis (UC) is an inflammatory chronic intestinal disease with pathological characteristics, including imbalanced immune function and the overexpression of inflammatory cytokines and mediators. Inflammatory cytokines (tumor necrosis factor (TNF)- $\alpha$, interleukin (IL)-1, and IL-6) were oversecreted in UC condition. Cyclooxygenase (COX)-2 and prostaglandin (PG) $\mathrm{E}_{2}$ were also overexpressed in colon tissue. Lingonberry (LB) (Vaccinium vitis-idaea L.) possesses pharmacological activities, including anti-oxidant, anti-cancer, and anti-obesity effects. To explore LB's effects on UC, BALB/c mice were administered with $3 \%(\mathrm{w} / \mathrm{v})$ dextran sulphate sodium (DSS) and LB extract (70\% ethanol) orally for nine days. The severity of UC was measured by the change in body weight and colon length. To evaluate LB's regulatory effect on inflammatory cytokines, the enzyme-linked immunosorbent assay (ELISA) kit was used to measure the inflammatory cytokines in mouse serum. Mouse peritoneal microphages were used to detect LB's anti-inflammatory effect. The results showed that LB treatment ameliorated less weight loss and longer colon length compared to the DSS-treated group. LB treatment also ameliorated the secretion of inflammatory cytokines. These results indicated that LB has potential as an herbal medicine to treat UC.
\end{abstract}

Keywords: lingonberry; ulcerative colitis; inflammation; nitric oxide; dextran sulphate sodium

\section{Introduction}

Inflammatory intestinal diseases, including ulcerative colitis (UC) and Crohn's disease (CD), have a high re-occurrence ratio. These diseases cause chronic abnormal inflammation in intestinal tissues [1]. Dietary habits, genetics, and irregular lifestyles such as stress factors, alcoholism, or drug abuse increase a person's probability of developing UC [2].

$\mathrm{UC}$ is an increasing global health problem, yet little is known about its etiology. Currently, researchers recognize that UC is characterized by localized inflammatory symptoms in the submucosa or mucosa and inflammation in the large intestine [3]. Major clinical symptoms include diarrhea, abdominal pain, weight loss, and bloody stool causing inflammatory cell infiltration and colon length shortening. These symptoms can cause the life quality for UC patients to deteriorate [4]. If left untreated, UC can cause further complications, including colorectal cancer or peritonitis [5]. To prevent these secondary complications, treatment is necessary.

Despite there being little identification of the etiological causes of UC, various therapies such as 5-aminosalicylic acid (5-ASA) agents, immunosuppressive agents, and corticosteroids are available, but their side effects include nausea, fever, and a loss of appetite. 
Long-term use of these therapies can result in kidney disorder, vascular disease, and hepatotoxicity [6]. The therapeutic agents stop diarrhea and reduce pain, but the relief is only temporary [7]. Finding therapeutic agents, especially ones that are of natural origin with long-lasting relief and no side effects, is crucial for UC patients.

Our UC mice model, induced with dextran sulphate sodium (DSS) (molecular weight: 36,000-50,000), exhibited UC symptoms including bloody stools, epithelial injury, ulceration, and inflammatory cell infiltration [8]. Crypt abscesses, epithelioglandular hyperplasia, and increased inflammatory cell infiltration were also observed [9]. These UC symptoms and colon conditions in the mouse model were similar to those of humans. This indicated that the UC mouse model-induced DSS was appropriate for studying the mechanism of therapeutic agents.

Lingonberry (LB) (Vaccinium vitis-idaea L.) contains pharmacological constituents, including anthocyanin, ellagitannin and phenolic acid [10]. LB is a reddish-colored berry that grows in Eurasia and North America. The phenolic compound in berries, such as LB, blueberry, cranberry and chokeberry, help treat oxidative disease [11]. LB is traditionally used in food not only for its red color, but also for its rich vitamins and polyphenols [12]. Previous studies have evaluated the pharmacological effects of LB on obesity [13], glucose metabolism [14], inflammation [15], oxidative stress [16], antibacterial activity [17], and cancer [18]. Moreover, the phenolic content of LB has anti-oxidant activity and antiinflammatory effects on RAW264.7 cells [19]. To date, however, the effect of LB on UC has not been studied.

Various studies suggest that an inflammatory response is a consequence of the interaction between immune-mediated cells (dendritic cells and macrophages) and antigens [20]. Macrophage activation induces UC via microbacterial factors such as lipopolysaccharides (LPS), and releases inflammatory-mediated factors containing interleukin (IL)-1 $\beta$, IL-6, tumor necrosis factor (TNF)- $\alpha$, and nitric oxide (NO). UC patients have been shown to have increased level of inflammation mediators [5]. Mouse macrophages have been used to investigate the effect of LB on UC.

In this study, we demonstrated LB's anti-inflammatory activities in a UC mouse model by DSS administration.

\section{Materials and Methods}

\subsection{Reagents}

5-ASA and 3-(4,5-dimethylthiazol-2-yl)-2,3-diphenyltetrazolium bromide (MTT) were purchased from Glentham Life Sciences Ltd. (Leanfield, Corsham, UK). DSS (molecular weight: 36,000-50,000) was provided by MP Biomedicals, LCC (Irvine, CA, USA). Sodium nitrite, sulfanilamide, $\mathrm{N}$-1-(naphthyl)-ethylene diamide, eosin, and Tween 20 were obtained from Sigma-Aldrich (St. Louis, MO, USA). Inducible nitric oxide synthase (iNOS) and glyceraldehyde 3-phosphate dehydrogenase (GAPDH) primary antibodies were provided by Cell Signaling Technology (Danvers, MA, USA). TNF- $\alpha$, IL-1 $\beta$, and IL-6 ELISA kits were purchased from BioLegend (San Diego, CA, USA). A prostaglandin $\mathrm{E}_{2}\left(\mathrm{PGE}_{2}\right)$ ELISA kit was provided by Enzo Bioscience (Farmingdale, NY, USA). Hematoxylin was obtained from Muto Pure Chemicals Co. (Tokyo, Japan).

\subsection{Preparation of LB Extract}

The powder of dried LB fruit was purchased from HAENA Food (Seoul, Korea). The powder of LB was extracted with $70 \%$ ethanol under reflux at $70{ }^{\circ} \mathrm{C}$ for $3 \mathrm{~h}(50 \mathrm{~g} / \mathrm{L})$. The ethanol solvent was filtered with filter paper (ADVANTEC, Tokyo, Japan). The filtered solvent was evaporated using a rotary evaporator at $45^{\circ} \mathrm{C}$. Then the solvent was freezedried at $-45^{\circ} \mathrm{C}, 5 \mathrm{~m}$ Torr. The yield of the dried extract was $11.26 \%$. The LB extract was diluted in distilled water and filtered through a $0.22 \mu \mathrm{m}$ syringe filter (HYUNDAI Micro, Seoul, Korea). A voucher specimen (JUHES-1665) was deposited at the Department of Oriental Medicine Resources, Jeonbuk National University (Iksan, Korea). 


\subsection{Animals}

BALB/c mice (male, 6 weeks, $22 \pm 1 \mathrm{~g}$ ) and C57BL/ 6 mice (male, 6 weeks, $20 \pm 1 \mathrm{~g}$ ) were supplied by SAMTACO (Osan, Korea). All mice were provided with tap water and group housing under standard conditions $\left(20-24^{\circ} \mathrm{C} ; 40-60 \%\right.$ humidity) throughout the study. The mice were acclimated for seven days and divided randomly into five experimental groups, each containing six mice per cage. The mice were sacrificed on day 9 , and their colons were collected. After the length of the colons was measured, the colons were cut into small pieces (approximately 2 to $3 \mathrm{~cm}$ ) and kept in $15 \mathrm{~mL}$ tubes. The tips of the colons (approximately $8 \mathrm{~mm}$ ) were fixed in formalin for histological analysis. The experimental schedule and procedure (2017-0086) were allowed by the Committee on the Care of Laboratory Animal Resources, Jeonbuk National University.

\subsection{Induction of Colitis}

To induce UC, the drinking water was contaminated with 3\% (w/vol) DSS for 9 days naturally in the male BALB/c mice. The mice were bred into five randomly divided groups $(\mathrm{n}=6)$ : a Blank group (distilled water orally once per a day), DSS group (3\% DSS with distilled water orally once per a day), LB 10 group ( $3 \%$ DSS with $10 \mathrm{mg} / \mathrm{kg}$ LB orally once per a day), LB 100 group (3\% DSS with $100 \mathrm{mg} / \mathrm{kg}$ LB orally once a day), and 5-ASA group ( $3 \%$ DSS with $50 \mathrm{mg} / \mathrm{kg} 5$-ASA orally once per a day). Gross bleeding in the stool or at the anus, stool condition, and bodyweight were recorded daily to estimate UC activity index. At the end of each experimental day, a blood sample was drawn from the orbital vein under diethyl ether anesthesia.

\subsection{Disease Activity Index (DAI)}

To assess the severity of UC, the DAI score was used in this experiment. Body weight, gross bleeding, and stool condition were recorded daily (Table 1). The DAI score was evaluated as the score average for the criteria mentioned.

$$
\mathrm{DAI}=\{(\text { weight loss })+(\text { diarrhea score })+(\text { rectal bleeding score })\} / 3
$$

Table 1. Criteria of disease activity index (DAI).

\begin{tabular}{cccc}
\hline Score & Weight Loss (\%) & Stool Consistency & Gross Bleeding \\
\hline 0 & None & Normal & Negative \\
1 & $1-5$ & Loose stool & Negative \\
2 & $5-10$ & Loose stool & Positive \\
3 & $10-20$ & Diarrhea & Positive \\
4 & $>20$ & Diarrhea & Gross bleeding \\
\hline
\end{tabular}

\subsection{Enzyme-Linked Immunosorbent Assay (ELISA)}

Mouse serum samples were prepared and subjected at the end of each experimental day to measurement of serum TNF- $\alpha$, IL- $1 \beta$, and IL- 6 using the ELISA kit. In brief, $100 \mu \mathrm{L}$ of capture antibodies were added to each well of the 96-well plates and then incubated at $4{ }^{\circ} \mathrm{C}$ overnight. After each well was washed with $0.05 \%$ phosphate buffered saline containing Tween 20 (PBST), $100 \mu \mathrm{L}$ of each serum sample was added into each well and incubated at room temperature (RT) for $3 \mathrm{~h}$. The 96-well plates were washed three times, then $100 \mu \mathrm{L}$ of detection antibodies were added to each well and incubated at RT for $1 \mathrm{~h}$. Next, each well was coated with $50 \mu \mathrm{L}$ of avidin-HRP for $30 \mathrm{~min}$. A substrate mixture $100 \mu \mathrm{L}$ was added and reacted into each well, and the plates were incubated at RT for $35 \mathrm{~min}$ in a light-blocked place. Absorbance was determined with a VersaMax microplate reader (Molecular Devices, Sunnyvale, CA, USA) at $450 \mathrm{~nm}$ wavelength.

\subsection{Western Blotting Analysis}

The mice were sacrificed on day 9 and the colons were dissected $(8-10 \mathrm{~mm})$ and flushed with PBS to perform Western blot analysis. The colon segments from each group 
were homogenized with PRO-PREP lysis buffer (iNtRON Biotech, Seongnam, Korea) for $1 \mathrm{~h}$ on ice. The lysates were centrifuged at $15,000 \mathrm{~g}$ for $15 \mathrm{~min}$ at $4{ }^{\circ} \mathrm{C}$. The supernatants were moved to a $1.5 \mathrm{~mL}$ distilled tube. Concentrations of protein were quantified by a detergent compatible (DC) protein assay kit (Bio-Rad Laboratories, Inc., Hercules, CA, USA) according to the producer's protocol. The protein extract samples (30 $\mu \mathrm{g}$ protein) were separated by $10 \%$ sodium dodecyl sulfate (SDS)-polyacrylamide gel electrophoresis. The separated protein was transferred to polyvinylidenedifluoride (PVDF) membrane (Merck, Temecula, CA, USA). The membranes were blocked with $5 \%$ non-fat milk in $0.05 \%$ PBS-Tween 20 (PBST) for $1 \mathrm{~h}$ at RT. Next, the primary antibodies of iNOS and GAPDH (dilution, 1:1000) were incubated with the membranes overnight at $4{ }^{\circ} \mathrm{C}$. The membranes were washed three times with $0.05 \%$ PBST then incubated with horseradish peroxide (HRP)-conjugated anti-rabbit and anti-mouse 2 nd antibodies (dilution, 1:10,000) for $1 \mathrm{~h}$ at RT. Antibody-specific proteins were identified using Western blot luminol reagent (Santa Cruz Biotechnology, Dallas, TX, USA) and visualized with the LAS-4000 image reader (Fujifilm Life Science, Tokyo, Japan). The concentrations of the protein bands were quantified using the Image J software (NIH).

\subsection{Hematoxylin and Eosin Staining (HEE Staining)}

The entire colon of each mouse was dissected and washed with cold PBS. About 5-8 $\mathrm{mm}$ of rectum sections were fixed in 10\% neutral buffered formalin (Sigma-Aldrich) for $24 \mathrm{~h}$ at RT. Then sections were embedded in paraffin $(0.4 \mu \mathrm{m})$ to provide slices for histological estimation. These colon slices were stained with hematoxylin and eosin. The score of histological injury was determined based on the previously described criteria [21] (Table 2).

Table 2. Criteria for assessment of microscopic rectal damage.

\begin{tabular}{cc}
\hline Score & Remarks \\
\hline 0 & Normal colonic mucosa \\
1 & Loss of one-third of the crypts \\
2 & Loss of two-thirds of the crypts \\
3 & Lamina propria covered with single layer of epithelial cells with mild \\
4 & inflammation cell infiltration \\
\end{tabular}

\subsection{Immunohistochemistry (IHC)}

IHC was carried out as described previously [22]. All paraffin sections were deparaffinized using xylene and rehydrated using ethyl alcohol and distilled water. The retrieval of antigens was performed in citrate buffer ( $\mathrm{pH}$ 6.0, $10 \mathrm{mM}$ citrate buffer with Tween 20) for $10 \mathrm{~min}$ in the microwave. Experimental slides were blocked with $3 \% \mathrm{H}_{2} \mathrm{O}_{2}$ for $10 \mathrm{~min}$ for endogenous peroxidase activity and pre-blocked with a normal blocking serum for $10 \mathrm{~min}$. Then the slices were incubated with a primary antibody in block buffer (1:50) at $4{ }^{\circ} \mathrm{C}$ overnight. After that, all slides were washed three times with tris-buffered saline (TBS) with $0.1 \%$ Tween-20 (TBST), and the following processes were performed with the Universal Quick kit (Vectastain, Vector Laboratories, Inc., Burlingame, CA, USA) according to the producer's procedure. All the slides were stained with peroxide substrate solution (Vectastain) and counter-stained with hematoxylin for $10 \mathrm{~min}$. All experimental slides were secured with a mounting solution and cover slips. Experimental images were observed through optical microscopy (Primo Star, Zeiss, Berlin, Germany).

\subsection{Prostaglandin (PG) $E_{2}$ Assay}

The mouse colons were washed with cold PBS and stored at $-75^{\circ} \mathrm{C}$ immediately until the experiment. The colon tissues were homogenized with $1 \mathrm{~mL}$ ice-cold lysis solution (10 mM Tris-HCI (pH 7.4), 1\% protease and phosphatase inhibitor cocktail, and $1 \mathrm{mM}$ EDTA, $10 \mu \mathrm{M}$ indomethacin (Sigma, Saint Louis, MO, USA)). The tissue homogenates were moved to microcentrifuge tubes and centrifuged at $4{ }^{\circ} \mathrm{C}$ at $13,000 \times \mathrm{g}$ for $10 \mathrm{~min}$. The 
protein concentrations in the supernatants $(5 \mu \mathrm{L})$ were analyzed by a DC Protein Assay Kit (Bio-rad) according to the producer's procedure. The measurement of $\mathrm{PGE}_{2}$ levels was carried out using a PGE $_{2}$ ELISA Kit (Enzo bioscience, Farmingdale, NY, USA). All samples were diluted in assay buffer in a ratio of 1:100. The experiments were performed in triplicates and a standard curve was created at the same time. Absorbance was measured using the Versamax microplate reader at $405 \mathrm{~nm}$.

\subsection{Quantitative Real-Time Polymerase Chain Reaction ( $q$ RT-PCR)}

The primer sequences are shown in Table 3. Briefly, the total RNA of cells was extracted with the easy-BLUE total RNA extraction kit (iNtRON) according to the manufacturer's protocol. The extracted total RNA was reverse transcribed into cDNA using the AMPIGENE ${ }^{\circledR}$ cDNA Synthesis Kit (Enzo Bioscience, Farmingdale, NY, USA) and qRT-PCR amplification was conducted with the SYBR Green reagent to measure the relative mRNA expressions of IL- $1 \beta$, TNF- $\alpha$, and IL- 6 .

Table 3. Primer sequenced for qRT-PCR.

\begin{tabular}{ccc}
\hline Gene & Forward & Reverse \\
\hline Mouse IL-1 $\beta$ & CCTTCCAGGATGAGGACATGA & TGAGTCACAGAGGATGGGCTC \\
Mouse IL-6 & GAGGATACCACTCCCAACAGACC & AAGTGCATCATCGTTGTTCATACA \\
Mouse TNF- $\alpha$ & CAGGCGGTGCCTATGTCTC & CGATCACCCCGAAGTTCAGTAG \\
Mouse IFN- $\gamma$ & ACACTGCATCTTGGCTTTGC & CCAGTTCCTCCAGATATCCA \\
Mouse iNOS & CAGCTGGGCTGTACAAAC & CATTGGAAGTGAAGCGATTCG \\
Mouse GAPDH & CCATCACCATCTTCCAGGAG & CCTGCTTCACCACCTTCTTG \\
\hline
\end{tabular}

\subsection{Determination of Myeloperoxidase (MPO) Activity}

Myeloperoxidase (MPO) activities were measured, and, in the process, neutrophil infiltration of the colon was assessed indirectly. Mid-colon sections were homogenized with EDTA/ $\mathrm{NaCl}$ buffer ( $\mathrm{pH} 4.7$ ) and then centrifuged at $12,000 \times g$ for $15 \mathrm{~min}$. The homogenized colons were re-suspended in $0.5 \%$ hexadecyltrimethyl ammonium bromide buffer ( $\mathrm{pH}$ 5.4). The colon samples were deep-frozen in liquid nitrogen and defrosted three times repeatedly. Samples were centrifuged again and then the $25 \mu \mathrm{L}$ supernatant was used for the MPO activity measurement. The enzyme reaction was performed with the addition of $25 \mu \mathrm{L}$ of $\mathrm{NaPO}_{4}, 1.6 \mathrm{mM}$ tetramethylbenzidine (TMB) in $80 \mathrm{mM}$, and $0.3 \mathrm{mM}$ $\mathrm{H}_{2} \mathrm{O}_{2} 100 \mu \mathrm{L}$. The MPO activity of each sample was measured with a Versamax microplate reader at $560 \mathrm{~nm}$ wavelength and the results were represented as density per milligram of colon tissue.

\subsection{Isolation and Culture of Peritoneal Macrophages}

C57BL / 6 male mice were administered with an intraperitoneal (IP) injection of $4 \%$ thioglycolate (TG) solution (3 mL) and sacrificed on the third day after injection. Peritoneal cavities were washed with Dulbecco's modified Eagle's medium (DMEM) (5 mL). The peritoneal lavage fluid was centrifuged at $6000 \times g$ for $5 \mathrm{~min}$. The cells were re-suspended in DMEM and seeded into 24-well microplates. These cells were cultured at $37^{\circ} \mathrm{C}$ for 24 or $48 \mathrm{~h}$ in DMEM plus $10 \%$ fetal bovine serum (FBS).

\subsection{Cell Viability Assay}

To investigate cell viability, thiazolyl blue tetrazolium bromide (MTT) was used. Mice peritoneal macrophages were pre-treated with $\operatorname{LB}(1,10,100$, or $1000 \mu \mathrm{g} / \mathrm{mL})$ for $24 \mathrm{~h}$. MTT solution $(0.5 \mathrm{mg} / \mathrm{mL})$ was then added and incubated over $4 \mathrm{~h}$. After incubation, the supernatant was eliminated, and the formazan crystals were liquefied in $650 \mu \mathrm{L}$ of dimethyl sulfoxide (DMSO). The absorbance of each well at $540 \mathrm{~nm}$ wavelength was determined with the Versamax microplate reader. 


\subsection{Measurement of Nitric Oxide Level}

Mouse peritoneal macrophages were pre-treated with LB (1-1000 $\mu \mathrm{g} / \mathrm{mL})$ for $4 \mathrm{~h}$. Next, they were treated with $1 \mu \mathrm{g} / \mathrm{mL}$ of LPS and incubated for $48 \mathrm{~h}$. After incubation, the supernatants were collected for NO determination. To measure the nitrite oxide level, a same volume of Griess reagent $\mathrm{A}$ and $\mathrm{B}(1 \%$ sulfanilamide in distilled water $/ 0.1 \%$ naphtylethyenediamine dihydrochloride in $5 \% \mathrm{H}_{3} \mathrm{PO}_{4}$ ) was mixed with the supernatant at $\mathrm{RT}$ for $10 \mathrm{~min}$. The Versamax microplate reader measured the absorbance at a wavelength of $540 \mathrm{~nm}$ to determine nitrite concentration. $\mathrm{NaNO}_{2}$ was used to obtain the standard curve.

\subsection{Statistical Analysis}

The Graph Pad Prism software 5.0 analyzed the results, which were presented as the mean \pm S.D. (standard deviation) of at least three experiments separately. Statistical evaluation was identified by using a Bonferroni's post-hoc analysis and one-way analysis of variance (ANOVA). A $p$-value of $<0.05$ was considered a statistically significant difference.

\section{Results}

\subsection{Effect of LB on Clinical Signs in DSS-Induced UC Mice}

BALB/c mice were orally administered 3\% DSS and LB $10 \mathrm{mg} / \mathrm{kg}$, LB $100 \mathrm{mg} / \mathrm{kg}$, and 5-ASA $50 \mathrm{mg} / \mathrm{kg}$ daily for nine days to regulate UC condition. 5-ASA was used as the positive control. The DSS group had significant body weight loss compared to the Blank group. In both LB groups, loss of body weight was attenuated compared to the DSS group (Figure 1a) (Blank group, $23.5 \pm 0.80 \mathrm{~g}$; DSS group, $20.3 \pm 1.03 \mathrm{~g}$; LB 10 group, $23.0 \pm 0.26 \mathrm{~g}$; LB 100 group, $22.6 \pm 0.95 \mathrm{~g}$; 5-ASA group, $22.0 \pm 0.92 \mathrm{~g}$ ). The DAI score was measured during the experimental period. The DAI score was significantly elevated in the DSS group, but the administration of LB $100 \mathrm{mg} / \mathrm{kg}$ decreased the DAI score (Figure $1 \mathrm{~b}$ ). LB $100 \mathrm{mg} / \mathrm{kg}$ was more effective than LB $10 \mathrm{mg} / \mathrm{kg}$ on the suppression of the DAI score ( $3 \%$ DSS group, $3.7 \pm 0.5 ;$ LB $100 \mathrm{mg} / \mathrm{kg}$ group, $2.3 \pm 0.5 ; \mathrm{LB} 10 \mathrm{mg} / \mathrm{kg}$ group, $3.2 \pm 0.8$; 5-ASA group, $2.3 \pm 0.6$ ).

\subsection{LB Administration Recovered Colon Length Shortening}

Colon length was assessed at the end of the experiment to evaluate the regulatory effect of LB. The average colon length was shorter in the DSS group compared to the Blank group (Blank group, $8.47 \pm 0.22 \mathrm{~cm}$; DSS group, $5.42 \pm 0.11 \mathrm{~cm}$ ). The colon length shortening slowed and improved in the LB group (DSS group, $5.42 \pm 0.11 \mathrm{~cm} ; \mathrm{LB} 10 \mathrm{mg} / \mathrm{kg}$ group, $6.57 \pm 0.42 \mathrm{~cm}$; LB $100 \mathrm{mg} / \mathrm{kg}$ group, $7.02 \pm 0.62 \mathrm{~cm}$; 5-ASA group, $7.43 \pm 0.10 \mathrm{~cm}$ ) (Figure 1c).

\subsection{LB Regulates the Histological Injury and MPO Activity}

H\&E staining was performed to evaluate the histological injury in colonic tissues. The inflammatory cell infiltration and crypt collapse were observed in DSS-treated colon tissues. LB $100 \mathrm{mg} / \mathrm{kg}$, however, suppressed colon tissue injury (Figure 2a). Myeloperoxidase (MPO) activity increased with 3\% DSS in the colon tissue, but decreased with LB $100 \mathrm{mg} / \mathrm{kg}$ (Blank group, $24.94 \pm 1.43 \mu \mathrm{M} / \mathrm{mg}$; DSS group, $40.49 \pm 2.97 \mu \mathrm{M} / \mathrm{mg}$; LB $10 \mathrm{mg} / \mathrm{kg}$ group, $42.86 \pm 0.15 \mu \mathrm{M} / \mathrm{mg}$; LB $100 \mathrm{mg} / \mathrm{kg}$ group, $20.62 \pm 1.33 \mu \mathrm{M} / \mathrm{mg}$; 5-ASA group, $27.82 \pm 1.01$ $\mu \mathrm{M} / \mathrm{mg}$ ) (Figure 2c). High lactate dehydrogenase (LDH) activity increased in the DSS group (Blank group, $60.90 \pm 9.43 \%$; DSS group, $100 \pm 5.29 \%$ ); however, it significantly reduced with LB $100 \mathrm{mg} / \mathrm{kg}$ administration (DSS group, $100 \pm 5.29 \%$; LB $10 \mathrm{mg} / \mathrm{kg}$ group, $102.47 \pm 3.05 \%$; LB $100 \mathrm{mg} / \mathrm{kg}$ group, $68.58 \pm 6.82 \%$; 5-ASA group, $68.69 \pm 7.91 \%$ ) (Figure 2d). These results indicated that LB could have a protective effect on DSS-treated colon injury. 


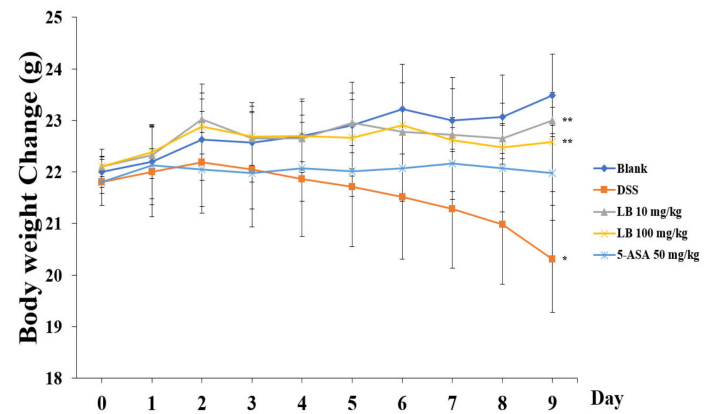

(a)

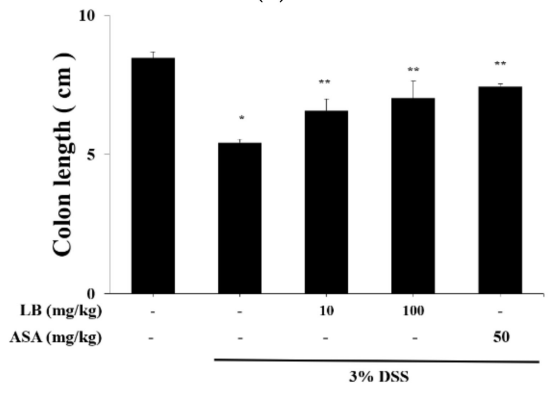

(c)

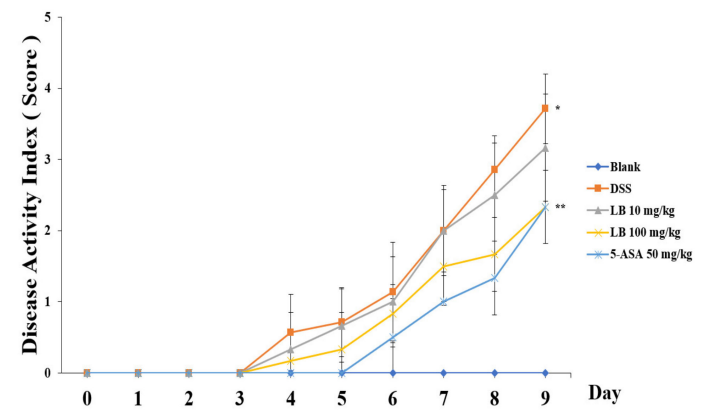

(b)

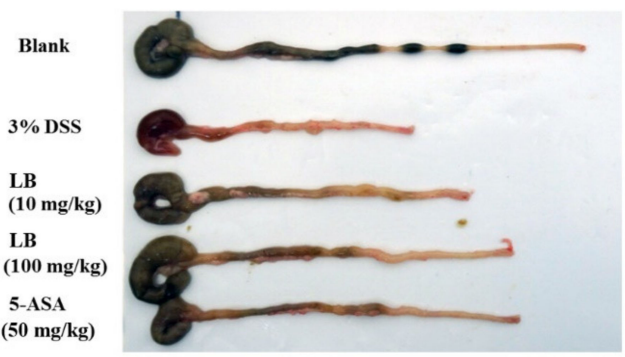

(d)

Figure 1. The effect of LB on clinical signs of UC in DSS-induced mice. The mice were administered with $3 \%$ DSS to induce UC, then LB and 5-ASA were given to treat UC clinical signs. (a) Body weight change; (b) disease activity index score; (c) colon length; (d) photograph of the colon. Values are represented as the mean \pm S.D. The data were analyzed by Bonferroni's post-hoc test. ${ }^{*} p<0.05$ versus Blank group and ${ }^{* *} p<0.05$ versus DSS group.

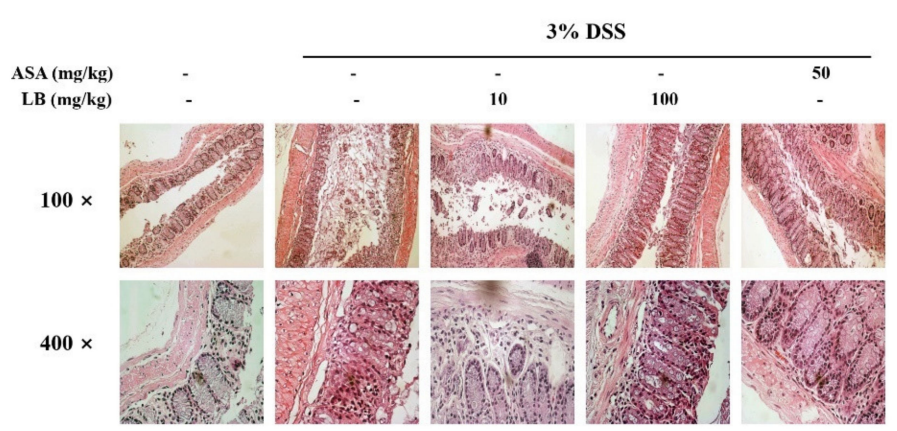

(a)

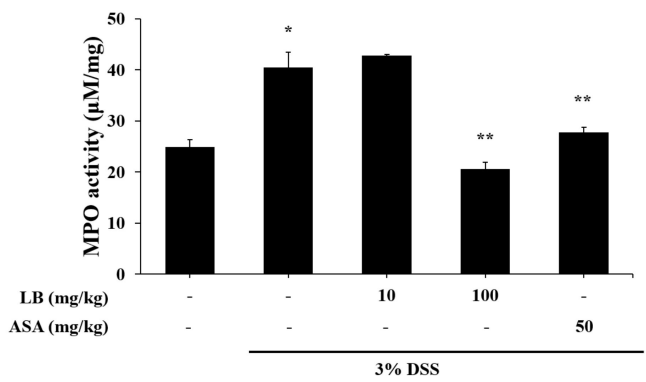

(c)

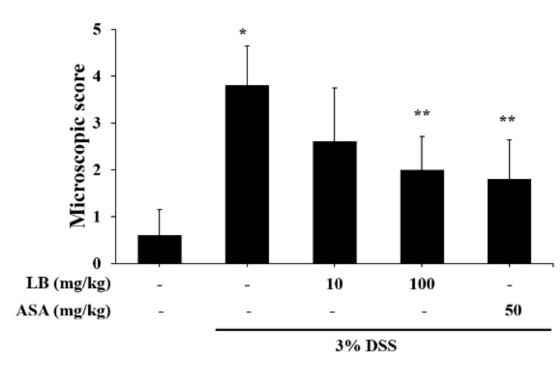

(b)

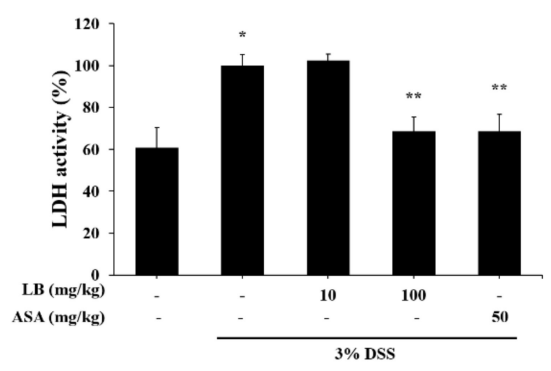

(d)

Figure 2. LB regulates histological injury and MPO activity. To induce UC, 3\% DSS was administered, and LB and 5-ASA were given to treat the histological injury. (a) Paraffin sections of colonic tissues were stained with H\&E and observed through a microscope (scale bar $=100 \times$ and $400 \times$ ); (b) microscopic score; (c) MPO activity; (d) LDH activity. Values are represented as the mean \pm S.D. The data were analyzed by Bonferroni's post-hoc test. ${ }^{*} p<0.05$ versus Blank group and ${ }^{* *} p$ $<0.05$ versus DSS group. 


\subsection{LB Decreases the Secretion of Inflammatory Cytokines in DSS-Induced UC Mouse Serum}

To determine LB's influence on inflammatory cytokine release, serum was gathered at the end of the experiment. ELISA calculated the secretion levels of inflammatory cytokines (TNF- $\alpha$, IL-1 $\beta$ and IL-6). In the serum, the secretion of cytokines was significantly increased in the DSS group compared to the Blank group. In the LB 100 group, the secretion of cytokines was noticeably lower than in the DSS group (Figure 3). In addition, $\mathrm{PGE}_{2}$ expression had the highest concentration in the DSS group (Blank group, $253.39 \pm 13.08 \mathrm{pg} / \mathrm{mL}$; DSS group, $1589.92 \pm 87.60 \mathrm{pg} / \mathrm{mL}$ ). The LB treatment, however, considerably suppressed $\mathrm{PGE}_{2}$ expression in the colon tissue (DSS group, $1589.92 \pm 87.60 \mathrm{pg} / \mathrm{mL}$; LB 10 group, $695.79 \pm 145.75 \mathrm{pg} / \mathrm{mL}$; LB 100 group, $397.24 \pm 61.54 \mathrm{pg} / \mathrm{mL}$ ) (Figure 3d). These results indicate that LB $(100 \mathrm{mg} / \mathrm{kg})$ was similar to $50 \mathrm{mg} / \mathrm{kg}$ of $5-\mathrm{ASA}$, which was used as the positive control.

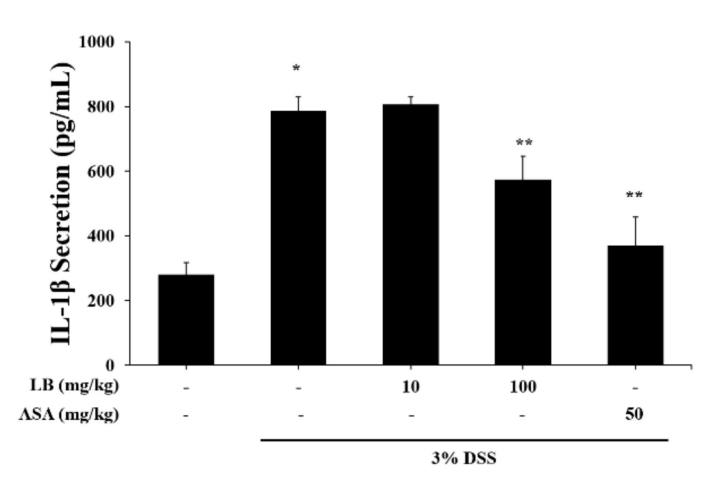

(a)

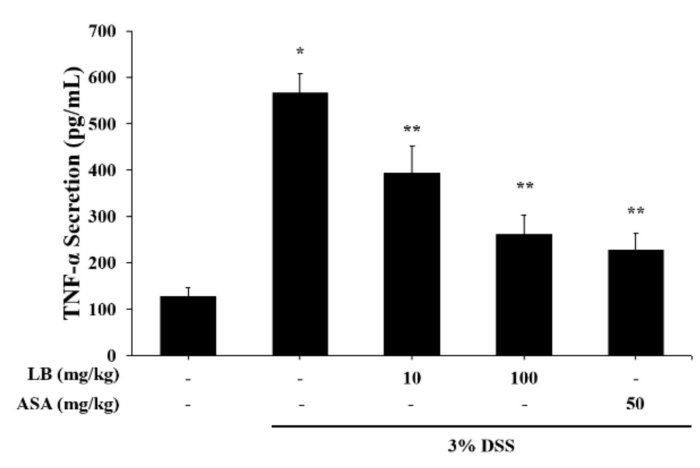

(c)

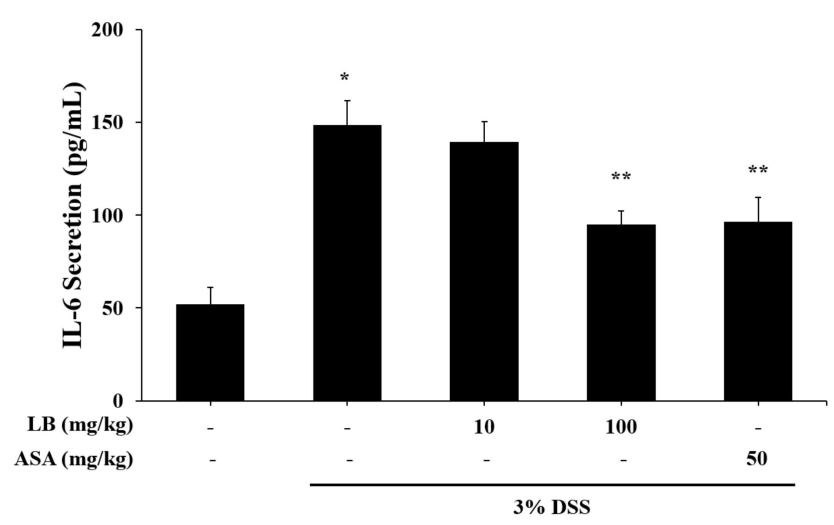

(b)

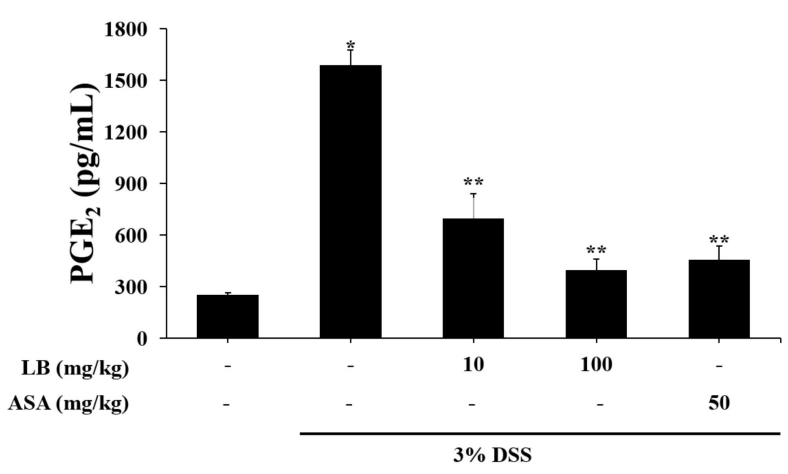

(d)

Figure 3. In DSS-induced mouse serum, LB significantly decreased the secretion of inflammatory cytokines ((a) IL-1 $\beta$, (b) IL-6, and (c) TNF- $\alpha$ ). The LB treatment also considerably suppressed (d) PGE 2 expression in the colon tissue. Values are represented as the mean \pm S.D. The data were analyzed by Bonferroni's post-hoc test. ${ }^{*} p<0.05$ versus Blank group and ** $p<0.05$ versus DSS group.

\subsection{LB Attenuates the Expression of Cyclooxigenase-2(COX-2), NF- $\kappa B$, and iNOS in} DSS-Induced UC Mice

IHC staining was carried out to measure the expression of COX-2, NF-kB, and iNOS in the mice's colonic tissue. NF- $\kappa B$ expression in the DSS group was highest among the experimental group, but NF- $\kappa B$ expression was significantly lower in the LB 100 group than in the DSS group (Figure 4). The expression of COX-2 and iNOS in the DSS group was higher than in the Blank group. The iNOS and COX-2 expressions were, however, remarkably low in the LB 100 group. 


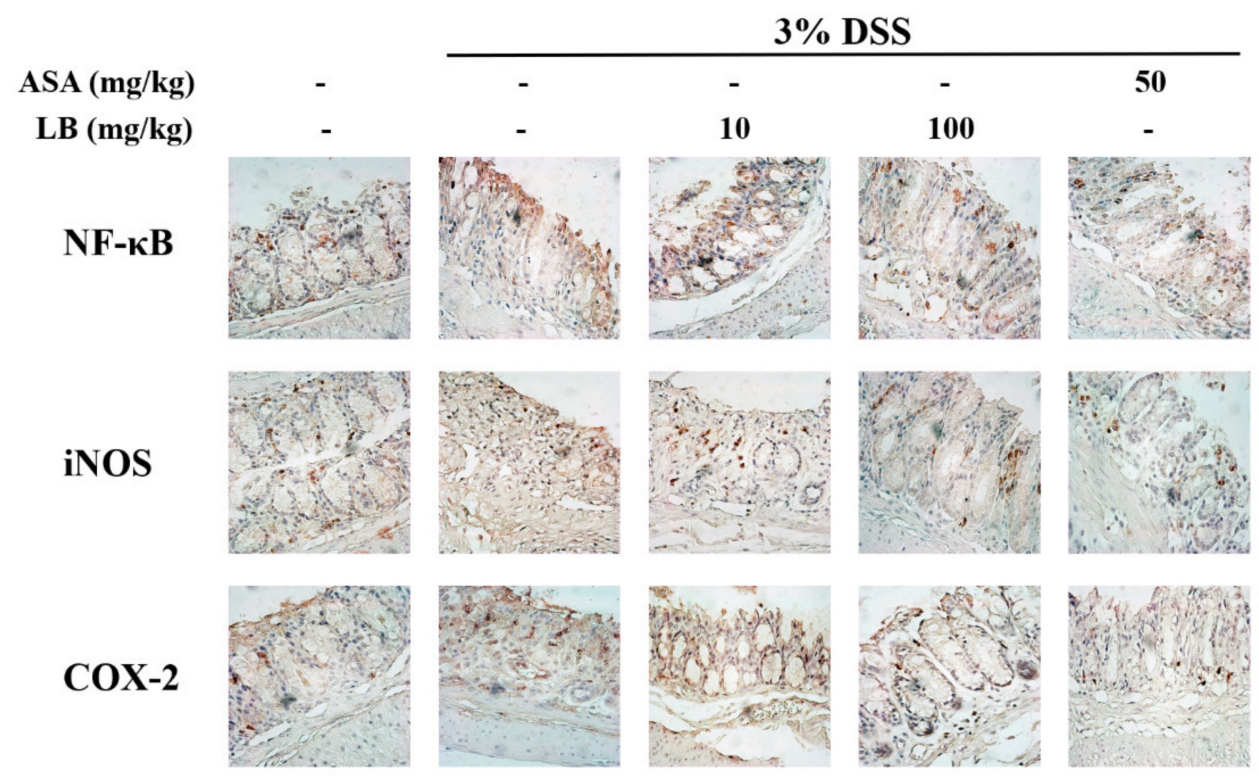

Figure 4. LB attenuated the expression of NF- $\mathrm{B}, \mathrm{COX}-2$, and iNOS in colon tissue in DSS-induced UC mice: expression of NF- $k$ B, iNOS, and COX-2 in colon tissue (scale bar $=100 \mu \mathrm{m}, 400 \times)$.

3.6. LB Regulates the mRNA Expression of Inflammatory Cytokines in LPS-Stimulated Peritoneal Mouse Macrophages

To evaluate LB's anti-inflammatory effect, a peritoneal macrophage was extracted from C57BL/ 6 mice. The peritoneal mouse macrophages were pre-treated with various concentrations of LB ( 0.1 to $1000 \mu \mathrm{g} / \mathrm{mL}$ ) for $24 \mathrm{~h}$, then cell viability was estimated with the MTT assay. The LB did not show cytotoxicity in the peritoneal mouse macrophages (Figure $5 \mathrm{a}$ ) that were stimulated with $1 \mu \mathrm{g} / \mathrm{mL}$ of LPS to secrete inflammatory cytokines. The IL-1 $\beta$ mRNA level increased with LPS stimulation only in the LPS-treated group and not the non-LPS group. The LB treatments $(10,100$, and $1000 \mu \mathrm{g} / \mathrm{mL})$ reduced the mRNA levels of IL-1 $\beta$ and IL-6 (Figure $5 b, c)$. LPS $(1 \mu \mathrm{g} / \mathrm{mL})$ stimulation increased the mRNA expression of TNF- $\alpha$ in peritoneal mouse macrophages, but the LB treatment decreased the TNF- $\alpha$ mRNA level (Figure 5d), as well as the IFN- $\gamma$ mRNA (Figure 5e). These results show that LB effectively regulated LPS-stimulated inflammation in peritoneal mouse macrophages.

\subsection{LB Regulates the NO Production in LPS-Stimulated Peritoneal Mouse Macrophages}

NO production increased when peritoneal mouse macrophages were stimulated with $1 \mu \mathrm{g} / \mathrm{mL}$ of LPS compared to the non-treatment group (non-treatment group, $54.99 \pm 1.05 \mu \mathrm{M}$; $1 \mu \mathrm{g} / \mathrm{mL}$ LPS treatment group, $252.04 \pm 2.51 \mu \mathrm{M})$. LB treatment decreased NO production, especially $1000 \mu \mathrm{g} / \mathrm{mL}$ of LB, which significantly reduced it $(1 \mu \mathrm{g} / \mathrm{mL}$ LPS treatment group, $252.04 \pm 2.51 \mu \mathrm{M} ; 1000 \mu \mathrm{g} / \mathrm{mL}$ LB treatment, $172.89 \pm 2.34 \mu \mathrm{M}$ ) (Figure 6a). The LB treatment regulated the mRNA level of iNOS in LPS-stimulated peritoneal mouse macrophages, and attenuated the protein expression of iNOS (Figure 6c). This result suggests that LB has an anti-inflammatory effect on macrophages. 


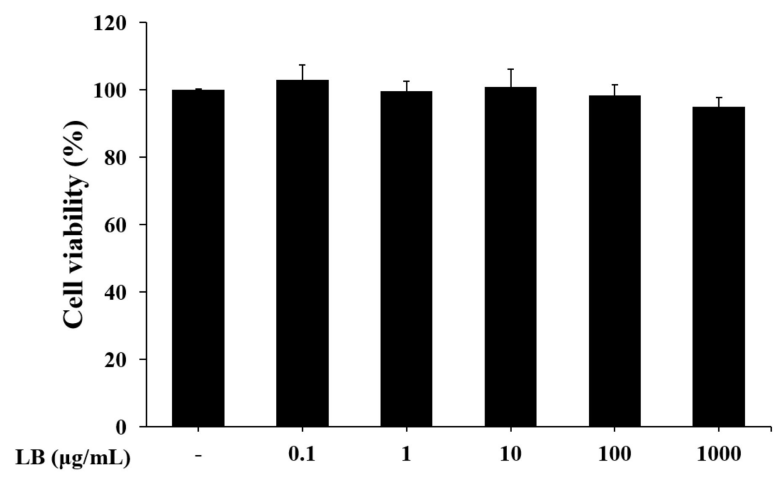

(a)

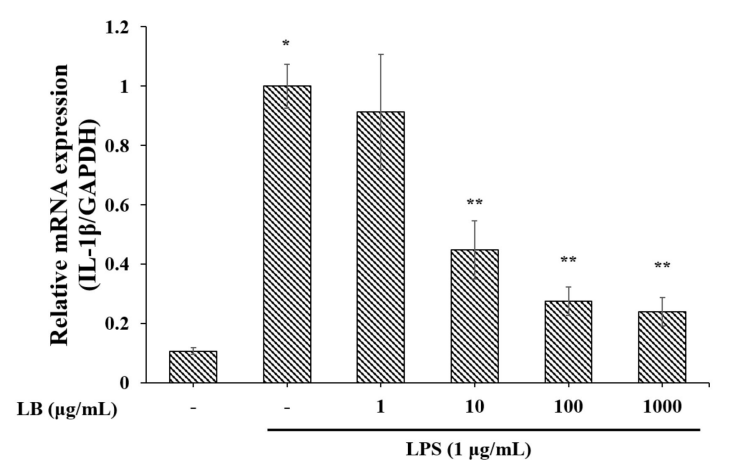

(b)



(d)



(c)

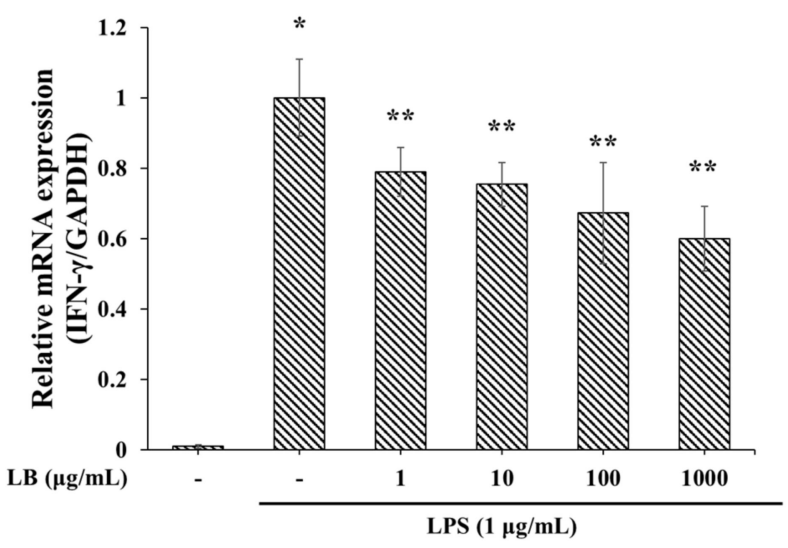

(e)

Figure 5. To determine (a) cell viability, an MTT assay was used. LB $(1,10,100$, or $1000 \mu \mathrm{g} / \mathrm{mL})$ did not show cytotoxicity in the peritoneal mouse macrophages. In LPS-stimulated peritoneal mouse macrophages, the LB treatments reduced the mRNA levels of (b) IL-1 $\beta$, (c) IL-6, (d) TNF- $\alpha$, and (e) IFN- $\gamma$. Values are represented as the mean \pm S.D. The data were analyzed by Bonferroni's post-hoc test. ${ }^{*} p<0.05$ versus normal group and ${ }^{* *} p<0.05$ versus LPS stimulation-only group. 


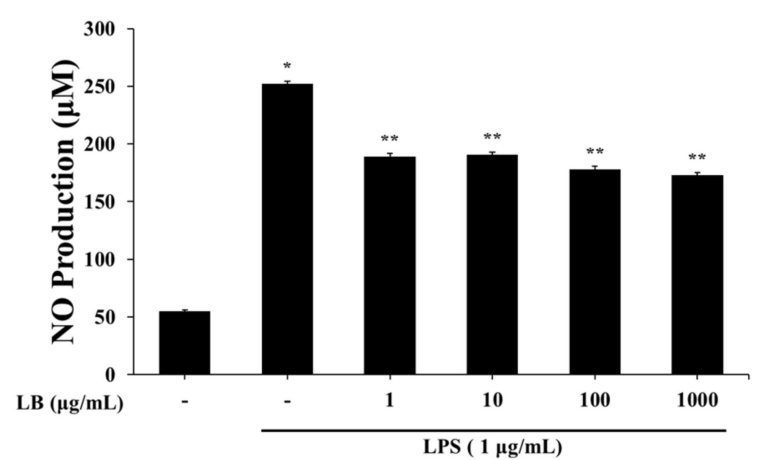

(a)

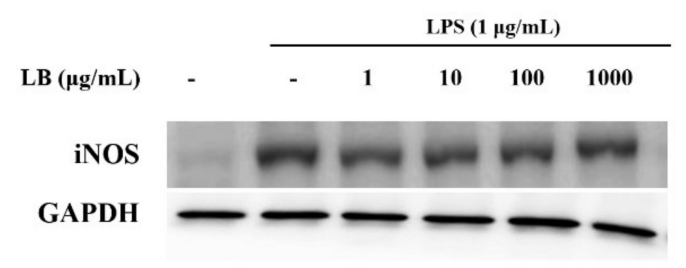

(c)

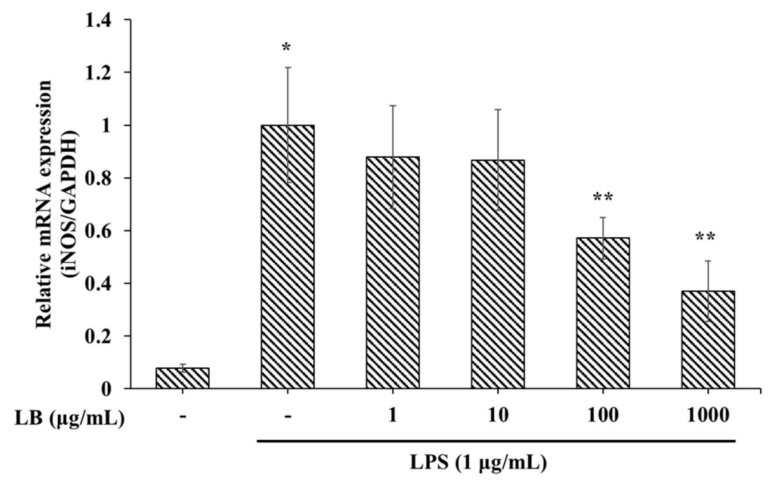

(b)

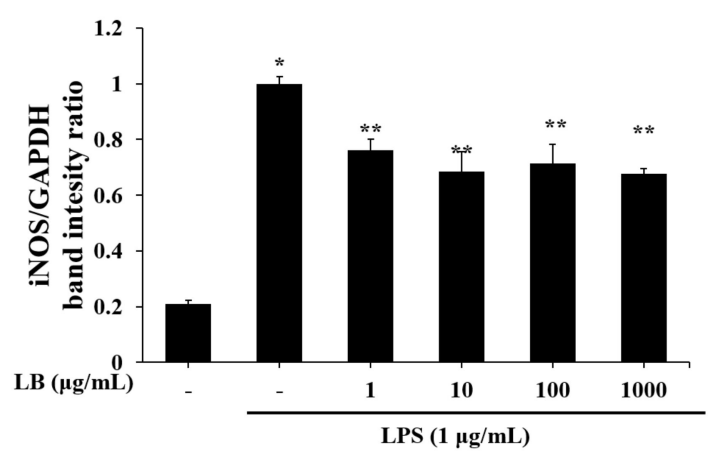

(d)

Figure 6. (a) NO level was measured by Griess assay. The LB treatment decreased NO production in LPS-stimulated peritoneal mouse macrophages, regulated (b) mRNA expression of iNOS, and attenuated (c) protein expression of iNOS. (d) The bar graph of the relative intensity of the Western blotting band by Image J. Values are represented as the mean \pm S.D. The data were analyzed by Bonferroni's post-hoc test. ${ }^{*} p<0.05$ versus normal group and ${ }^{* *} p<0.05$ versus LPS stimulation-only group.

\section{Discussion}

UC is a relapsing inflammatory chronic intestinal malady [23] that is worsened by an imbalanced inflammatory response and oxidative stress [24]. In addition, genetic factors, changes in environment, and an imbalanced immunological function can lead to difficulty in treating the intestinal inflammatory disease [25]. However, various drug treatments, including corticosteroids, immune modulators, and sulfasalazine, have serious side effects, such as poverty of blood, vomiting, and abdominal pain [26]. Therefore, the development of natural original products with few side effects is needed to treat chronic intestinal inflammatory disease.

Compared to various UC in vivo models, the DSS-induced UC model is appropriate as it mimics the characteristics of the disorder. Our DSS-induced mouse model exhibited UC symptoms including bloody stool, bodyweight loss, and diarrhea [27]. In this study, the administration of DSS worsened the clinical sign in vivo, but the LB treatment regulated the clinical sign of the DSS-induced mice. The administration of LB helped slow the bodyweight loss and decrease the DAI (diarrhea, occult/gross bleeding). Additionally, LB significantly slowed or stopped the colon length shortening caused by DSS (Figure 1). These results indicated that LB attenuated DSS-induced UC symptoms.

In inflammatory intestinal conditions, COX-2 leads to production of PG [28]. PGE $_{2}$ is over-expressed in UC colon tissue. Both $\mathrm{PGE}_{2}$ and COX-2 increase in the mucosa [29]. 5-ASA used in UC treatment inhibits COX-2 activation [30]. In our experiment, 5-ASA was also used as the positive control. However, LB $100 \mathrm{mg} / \mathrm{kg}$ showed more significant 
effects on the regulation of $\mathrm{PGE}_{2}$ (Figure 3) and COX-2 (Figure 4) activities than 5-ASA. These results suggest that LB extract can be a therapeutic agent for regulating intestinal inflammation. The transcription factor NF- $\mathrm{KB}$ modulates COX-2 synthesis and inflammatory cytokine secretion [31]. In IHC assay, intestinal NF- $\mathrm{kB}$ and iNOS expressions were increased by DSS drinking. However, those were particularly decreased due to LB $100 \mathrm{mg} / \mathrm{kg}$ administration. These experimental results suggest that the anti-UC effect of LB might be via COX-2 and NF-KB pathway.

$\mathrm{MPO}$, an enzyme found in neutrophil, is an indicator of neutrophil infiltration and the severity of inflammation [32]. $\mathrm{LDH}$, a ubiquitous enzyme, is released into the injured tissue or bloodstream [33]. The results showed that $100 \mathrm{mg} / \mathrm{kg}$ LB regulated MPO and LDH activity in DSS-induced colon tissue injury (Figure 2). The effect of LB administration on MPO and LDH activity also indicates the efficacy of ameliorating acute intestinal inflammation. Under DSS-induced UC condition, crypt damage and inflammatory cell infiltration occurred in inflamed areas and were relieved by LB administration (Figure 2). These results indicate that LB treatment suppressed DSS-induced colon damage.

Neutrophils, macrophages, and T cells release inflammatory cytokines (IL-1 $\beta$, IL- 6 , IFN- $\gamma$, and TNF- $\alpha$ ) that cause colon inflammation [34,35]. NO is also recognized as a regulator or mediator that induces inflammation [36]. Regulating inflammatory cytokines and NO is the strategy to remedy UC. In this study, LB suppressed the secretion of IL$1 \beta$, IL-6, TNF- $\alpha$, and IFN- $\gamma$ (Figure 5) and NO production (Figure 6) in LPS-stimulated peritoneal mouse macrophages. The interaction between the intestinal immune system and inflammatory cytokines could cause intestinal homeostasis and a disruption of tight junction factors [37]. Increased serum inflammatory cytokines (IL-1 $\beta$, IL-6, and TNF$\alpha$ ) by DSS administration were suppressed by LB administration, especially $100 \mathrm{mg} / \mathrm{kg}$ of LB extract. The anti-inflammatory and anti-UC efficacy were demonstrated through inflammatory cytokine inhibition in vivo and in vitro.

\section{Conclusions}

In conclusion, the LB treatment ameliorated the development and progression of UC in vivo and in vitro. $\mathrm{LB}$, especially $100 \mathrm{mg} / \mathrm{kg}$, regulated bodyweight loss, colon length shortening, and DAI in the DSS-induced UC mouse model. It also suppressed MPO activity and COX-2 and $\mathrm{PGE}_{2}$ expression in colon tissues, as well as reduced inflammatory cytokines (IL-1 $\beta$, IL-6, TNF- $\alpha$, and IFN- $\gamma$ ) and NO production in LPS-stimulated peritoneal mouse macrophages. LB treatment also suppressed the histological injury and inflammatory mediators (NF- $\mathrm{kB}$, iNOS) caused by DSS. This study suggests that LB is a potential therapeutic agent for UC.

Author Contributions: Conceptualization, H.M. and J.-S.J.; resources, J.-H.L. and S.-H.K.; data curation, J.-H.L. and Y.-D.J.; writing (original draft preparation), Y.-D.J. and J.-H.L.; writing (editing), J.-H.L., S.-H.K., H.M., and J.-S.J.; visualization, Y.-D.J. All authors have read and agreed to the published version of the manuscript.

Funding: This research was supported by the Basic Science Research Program through the National Research Foundation of Korea (NRF), funded by the Ministry of Education 2017R1A6A3A11032448. This paper was also supported by research funds from Jeonbuk National University in 2019.

Institutional Review Board Statement: All experimental protocols (2017-0086) were approved by the Committee on the Care of Laboratory Animal Resources, Chonbuk National University.

Informed Consent Statement: Not applicable.

Data Availability Statement: Datasets used and/or analyzed in the current study are available from the corresponding author on reasonable request.

Conflicts of Interest: The authors declare no conflict of interest. 


\section{References}

1. Cosnes, J.; Gower-Rousseau, C.; Seksik, P.; Cortot, A. Epidemiology and natural history of inflammatory bowel diseases. Gastroenterology 2011, 140, 1785-1794. [CrossRef]

2. Baumgart, D.C.; Carding, S.R. Inflammatory bowel disease: Cause and immunobiology. Lancet 2007, 369, 1627-1640. [CrossRef]

3. Kornbluth, A.; Sachar, D.B. Ulcerative colitis practice guidelines in adults (update): American College of Gastroenterology, Practice Parameters Committee. Am. J. Gastroenterol. 2004, 99, 1371-1385. [CrossRef] [PubMed]

4. Zheng, K.; Zhang, S.; Wang, C.; Zhao, W.; Shen, H. Health-related quality of life in Chinese patients with mild and moderately active ulcerative colitis. PLoS ONE 2015, 10, e0124211. [CrossRef] [PubMed]

5. Papadakis, K.A.; Targan, S.R. Role of cytokines in the pathogenesis of inflammatory bowel disease. Annu. Rev. Med. 2000, 51, 589-598. [CrossRef]

6. Yu, Y.R.; Rodriguez, J.R. Clinical presentation of Crohn's, ulcerative colitis, and indeterminate colitis: Symptoms, extra intestinal manifestations, and disease phenotypes. Semin. Pediatric Surg. 2017, 26, 349-355. [CrossRef] [PubMed]

7. Gilardi, D.; Fiorino, G.; Genua, M.; Allocca, M.; Danese, S. Complementary and alternative medicine in inflammatory bowel diseases: What is the future in the field of herbal medicine? Expert Rev. Gastroenterol. Hepatol. 2014, 8, 835-846. [CrossRef]

8. Jeon, Y.D.; Bang, K.S.; Shin, M.K.; Lee, J.H.; Chang, Y.N.; Jin, J.S. Regulatory effects of glycyrrhizae radix extract on DSS-induced ulcerative colitis. BMC Complementary Altern. Med. 2016, 16, 459. [CrossRef]

9. Toiyama, Y.; Mizoguchi, A.; Yoshinaga, O.; Koike, Y.; Morimoto, Y.; Araki, T.; Uchida, K.; Tanaka, K.; Nakashima, H.; Hidi, M.; et al. Intravital imaging of DSS-induced cecal damage in GFP-transgenic mice using two-photon microscopy. J. Gastoenterol. 2010, 45, 544-553. [CrossRef]

10. Ovaskainen, M.L.; Törrönen, R.; Koponen, J.M.; Sinkko, H.; Hellström, J.; Reinivuo, H.; Mattila, P. Dietary intake and major food sources of polyphenols in Finnish adults. J. Nutr. 2008, 138, 562-566. [CrossRef]

11. Zheng, W.; Wang, S.Y. Oxygen radical absorbing capacity of phenolics in blueberries, cranberries, chokeberries, and lingonberries. J. Agric. Food Chem. 2003, 51, 502-509. [CrossRef]

12. Mane, C.; Loonis, M.; Juhel, C.; Dufour, C.; Malien-Aubert, C. Food grade lingonberry extract: Polyphenolic composition and in vivo protective effect against oxidative stress. J. Agric. Food Chem. 2011, 59, 3330-3339. [CrossRef]

13. Heyman, L.; Axling, U.; Blanco, N.; Sterner, O.; Holm, C.; Berger, K. Evaluation of beneficial metabolic effects of berries in high-fat fed C57BL/6J mice. J. Nutr. Metab. 2014, 2014, 403041. [CrossRef]

14. Ryyti, R.; Hamalainen, M.; Peltola, R.; Moilanen, E. Beneficial effects of lingonberry (Vaccinium vitis-idaea L.) supplementation on metabolic and inflammatory adverse effects induced by high-fat diet in a mouse model of obesity. PLoS ONE 2020, 15, e0232605. [CrossRef]

15. Wang, S.Y.; Feng, R.; Bowman, L.; Penhallegon, R.; Ding, M.; Lu, Y. Antioxidant activity in lingonberries (Vaccinium vitis-idaea L.) and its inhibitory effect on activator protein-1, nuclear factor- $\mathrm{k}$, and mitogen-activated protein kinases activation. J. Agric. Food Chem. 2005, 53, 3156-3166. [CrossRef] [PubMed]

16. Kivimäki, A.S.; Siltari, A.; Ehlers, P.I.; Korpel, R.; Vapaatalo, H. Lingonberry juice negates the effects of a high salt diet on vascular function and low-grade inflammation. J. Funct. Foods 2014, 7, 238-245. [CrossRef]

17. Bhullar, K.S.; Rupasinghe, H.P.V. Antioxidant and cytoprotective properties of partridgeberry polyphenols. Food Chem. 2015, 169, 595-605. [CrossRef] [PubMed]

18. Tuulia, O.; Anne, K.; Matti, M.; Tuula, S.; Riitta, K. Anticancer effects of Lingonberry and bilberry on digestive tract cancers. Antioxidants 2021, 10, 850.

19. Mary, H.G.; Debora, E.; Kriya, L.D.; Mary, A.L. Comparative analysis of phenolic content and profile, antioxidant capacity, and anti-inflammatory bioactivity in wild Alaskan and commercial Vaccinium berries. J. Agric. Food Chem. 2014, 62, 4007-4017.

20. Oqata, H.; Hibi, T. Cytokine and anti-cytokine therapies for inflammatory bowel disease. Curr. Pharm. Des. 2003, 9, 1107-1113. [CrossRef]

21. Kihara, N.; de la Fuente, S.G.; Fujino, K.; Takahashi, T.; Pappas, T.N.; Mantyh, C.R. Vanilloid receptor-1 containing primary sensory neurones mediate dextran sulphate sodium induced colitis in rats. Gut 2003, 52, 713-719. [CrossRef]

22. Wang, J.; Zhang, T.; Ma, C.; Wang, S. Puerarin attenuates airway inflammation by regulation of eotaxin-3. Immunol. Lett. 2015, 163, 173-178. [CrossRef]

23. Dharmani, P.; Chadee, K. Biologic therapies against inflammatory bowel disease: A dysregulated immune system and the cross talk with gastrointestinal mucosa hold the key. Curr. Mol. Pharmacol. 2008, 1, 195-212. [CrossRef]

24. Strober, W.; Fuss, I.; Mannon, P. The fundamental basis of inflammatory bowel disease. J. Clin. Investig. 2007, 117, 514-521. [CrossRef] [PubMed]

25. Wu, L.H.; Xu, Z.L.; Dong, D.; He, S.A.; Yu, H. Protective effect of anthocyanins extract from blueberry on TNBS-induced IBD model of mice. Evid.-Based Complementary Altern. Med. 2011, 2011, 525462. [CrossRef] [PubMed]

26. Sandborn, W.J.; Targan, S.R. Biologic therapy of inflammatory bowel disease. Gastroenterology 2002, 122, 1592-1608. [CrossRef] [PubMed]

27. Rufo, P.A.; Bousvaros, A. Current therapy of inflammatory bowel disease in children. Pediatric Drugs 2006, 8, 279-302. [CrossRef] [PubMed]

28. Morita, I. Distinct functions of COX-1 and COX-2. Prostaglandins Other Lipid Mediat. 2002, 68, 165-175. [CrossRef] 
29. Wiercińska-Drapało, A.; Flisiak, R.; Prokopowicz, D. Effects of ulcerative colitis activity on plasma and mucosal prostaglandin E2 concentration. Prostaglandins Other Lipid Mediat. 1999, 58, 159-165. [CrossRef]

30. Lauritsen, K.; Laursen, L.S.; Kjeldsen, J.; Bukhave, K.; Hansen, T.K.; Rask-Madsen, J. Effects of mesalazine on the formation of lipoxygenase and cyclooxygenase products. Adv. Exp. Med. Biol. 1995, 371, 1301-1306.

31. Chen, C.C.; Sun, Y.T.; Chen, J.J.; Chiu, K.T. TNF- $\alpha$-induced cyclooxygenage-2 expression in human lung epithelial cells: Involvement of the phospholipase C- $\gamma 2$, protein kinase C- $\alpha$, tyrosine kinase, NF- $k B$-inducing kinase, and I- $\mathrm{kB}$ kinase $1 / 2$ pathway. J. Immunol. 2000, 165, 2719-2728. [CrossRef]

32. Coskun, M. Intestinal epithelium in inflammatory bowel disease. Front. Med. 2014, 2014, 24. [CrossRef] [PubMed]

33. Kim, H.S.; Lee, H.E.; Yang, H.K.; Kim, W.H. High lactate dehydrogenase 5 expression correlates with high tumoral and stromal vascular endothelial growth factor expression in gastric cancer. Pathobiology 2014, 81, 78-85. [CrossRef] [PubMed]

34. Kovacs-Nolan, J.; Zhang, H.; Ibuki, M.; Nakamori, T.; Yoshiura, K.; Turner, P.V.; Matsui, T.; Mine, Y. The PepT1-transportable soy tripeptide VPY reduces intestinal inflammation. Biochim. Biophys. Acta 2012, 1820, 1753-1763. [CrossRef] [PubMed]

35. Rose-John, S.; Waetzig, G.H.; Scheller, J.; Grötzinger, J.; Seegert, D. The IL-6/sIL-6R complex as a novel target for therapeutic approaches. Expert Opin. Ther. Targets 2007, 11, 613-624. [CrossRef]

36. Locksley, R.M.; Killeen, N.; Lenardo, M.J. The TNF and TNF receptor superfamilies: Integrating mammalian biology. Cell 2001, 104, 487-501. [CrossRef]

37. Abraham, C.; Medzhitov, R. Interactions between the host innate immune system and microbes in inflammatory bowel disease. Gastroenterology 2011, 140, 1729-1737. [CrossRef] 